\title{
Influência da presença de hábitos orais parafuncionais em vigília em indivíduos com disfunção temporomandibular dolorosa associada ou não a cefaleias
}

\author{
Juliana Homem Padilha Spavieri ${ }^{(D}$, Deise Isabela Moreira dos Anjos ${ }^{(D)}$, Guilherme Vinicius do Vale Braido ${ }^{(D)}$, \\ Juliana dos Santos Proença ${ }^{(D)}$, Daniela Aparecida de Godoi Gonçalves ${ }^{\text {(D) }}$
}

Faculdade de Odontologia da Universidade Estadual Paulista, Araraquara, São Paulo, Brasil

A disfunção temporomandibular (DTM) é uma condição musculoesquelética e neuromuscular de etiologia multifatorial. Está frequentemente associada à comorbidades dolorosas (cefaleias primárias, por exemplo) e à cefaleia atribuída à DTM (cDTM). Hábitos orais parafuncionais em vigília (HOV) podem influenciar essas condições dolorosas, piorando o prognóstico e aumentando a refratariedade ao tratamento. $O$ objetivo deste estudo transversal foi investigar a associação entre DTM, HOV, migrânea (Mg), cDTM e sintomas de depressão e ansiedade. A DTM foi classificada de acordo com o RDC/TMD, as variáveis sociodemográficas foram classificadas de acordo com os critérios do IBGE, a presença e frequência de HOV, os sintomas de depressão e de ansiedade foram coletados por meio de questionário. A Mg foi identificada de acordo com os critérios da Classificação Internacional de Cefaleias - $3^{a}$. Edição, e a cDTM de acordo com os critérios de Schiffman et al. (2014). A amostra, composta por 117 indivíduos com 20 a 65 anos de idade, foi estratificada em 4 grupos para estudos de associação: Controles; DTM; DTM+Mg; DTM+Mg+cDTM. As mulheres apresentaram DTM e cefaleias com maior frequência que os homens $(p<0,001)$. Houve associação significante entre maior grau de incapacidade relacionada à dor crônica da DTM e os grupos ( $p<0,0001$ ). A regressão logística multinomial apontou que na presença de maior frequência de HOV, os indivíduos tinham maiores chances de ter as 3 condições dolorosas simultaneamente (Odds Ratio $(O R)=3,23 ; I C=[1,06-9,81]$. O hábito de apertar os dentes em vigília aumentou as chances de os indivíduos apresentarem DTM+Mg e DTM+Mg+cDTM $(O R=1,81 ; \mathrm{IC}=$ $[1,25-2,64])$. Os resultados demonstram que a presença e a frequência dos HOV podem interferir na relação entre a DTM e as cefaleias, piorando o prognóstico e aumentando a chance de comorbidade entre estas patologias.

Palavras-chave: Síndrome de Disfunção da Articulação Temporomandibular, Bruxismo, Transtornos de Cefaleia Primários, Transtornos de Cefaleia Secundários. 